\title{
O ESTUDO DA METRÓPOLE E O USO DE INFORMAÇÕES GEORREFERENCIADAS
}

Gustavo de Oliveira Coelho de Souza

Haroldo da Gama Torres

\begin{abstract}
Resumo: A participação da Fundação Seade no Centro de Estudos da Metrópole - CEM estabeleceu o uso das ferramentas do Sistema de Informações Geográficas em projetos desenvolvidos de forma direta pela Fundação, ou em parceria com o CEM. Duas atividades destacam-se nesse processo: a consolidação de banco de dados e mapas digitais sobre a Metrópole e o desenvolvimento de novas metodologias de coleta e difusão de informações.

Palavras-chave: sistema de informações geográficas; Região Metropolitana; análise espacial.
\end{abstract}

\begin{abstract}
The participation of Fundação Seade in the Center for the Study of the Metropolis - CEM - established the use of the tools of Geographic Information System in projects developed directly by Seade, or in partnership with CEM. Two activities stand out in this process: the consolidation of the data bank and digitized maps of the metropolis and the development of new methodologies for gathering and disseminating this information. Key words: geographic information system; metropolitan region; spatial analysis.
\end{abstract}

A partir de 2000, a Fundação Seade passou a integrar o Centro de Estudos da Metrópole - CEM, em conjunto com o Cebrap - Centro Brasileiro de Análise e Planejamento, a Faculdade de Arquitetura e Urbanismo - FAU e a Escola de Comunicações e Artes ECA da USP e o Sesc São Paulo. Trata-se de um projeto financiado pela Fapesp, inserido no programa Centros de Pesquisa, Inovação e Difusão - Cepid, cujo objetivo é desenvolver atividades de pesquisa, transferência de conhecimento e difusão de informações a respeito da Região Metropolitana de São Paulo - RMSP.

Uma das novidades colocadas pelo CEM no tratamento de informações sobre a metrópole paulistana refere-se ao vínculo entre os resultados de pesquisas diretas (que envolve novas abordagens conceituais e metodológicas para as questões metropolitanas) e a consistência de dados secundários (tornando-se um centro de referência para a documentação e consolidação de informações e estudos sobre a RMSP). Os dados coletados e tratados são georreferenciados e difundidos por instrumentos como internet, seminários, palestras, workshops e publicações.

A constituição e a disponibilização das bases de dados no formato de Sistema de Informações Geográficas - SIG são atribuições do Seade como parceiro no projeto CEM, e estão inseridas no componente Inovação e Transferência de Tecnologia, cujos objetivos são:

- constituir um Sistema de Informações Georreferenciadas por meio da consolidação de dados espacializados para uso de planejadores urbanos e formuladores de políticas públicas;

- sistematizar, consolidar e disseminar informações sobre diferentes experiências no campo da política urbana, tornando o Centro um multiplicador nessa área;

- desenvolver aplicativos próprios para integrar dados de diversas origens;

- treinar profissionais para o uso de dados georreferenciados na formulação e implementação de políticas públicas urbanas.

Para tanto, a Fundação constituiu um grupo de trabalho que foi agregado à Divisão de Geoprocessamento e Estatísticas Espaciais - Digeo, que vincula-se à Gerência de Métodos Quantitativos - Gemec. Os trabalhos de geoprocessamento dos dois anos iniciais de estruturação do CEM centralizaram-se em três frentes:

- montagem do SIG georreferenciando informações cadastrais de equipamentos públicos (de educação e saúde) 
e mortalidade, existentes na Fundação, e a vetorização e consolidação da malha cartográfica digital dos setores censitários para os 21 municípios mais populosos da RMSP, para os censos demográficos de 1991 e 2000 e para a contagem populacional de 1996;

- a elaboração de projetos específicos a clientes e pesquisadores do CEM que envolveram a montagem de SIGs; e

- desenvolvimento de treinamentos para usuários dos SIGs (pesquisadores do CEM e do Seade e clientes do Centro que demandaram projetos georreferenciados).

A Fundação Seade habilitou-se a participar como parceiro do CEM no componente Inovação e Transferência de Tecnologia, porque já vinha desenvolvendo projetos que continham em seu escopo a elaboração e estruturação de sistemas de informações geográficas, cujo objetivo era suprir gestores públicos de um importante instrumento para a tomada de decisão. De fato, alguns exemplos podem ser dados, como o desenvolvimento de SIGs para a Diretoria de Planejamento da Sabesp e para a Central de Informações Educacionais da Secretaria da Educação do Estado de São Paulo. Contudo, os maiores desafios e avanços do uso do SIG no Seade deram-se com sua participação no CEM. $^{1}$

\section{GEOPROCESSAMENTO VOLTADO PARA POLÍTICAS PÚBLICAS}

As experiências que os pesquisadores da Fundação Seade e do Cebrap acumularam nos estudos sobre a Região Metropolitana já apontavam para a necessidade de um tratamento de dados que ultrapassavam as tradicionais unidades administrativas, como municípios e distritos, pois alguns fenômenos só poderiam ser compreendidos quando se descesse à escala intradistrital. $\mathrm{O}$ fato é que a falta de informações nesse nível de detalhe tem dificultado a formulação de políticas, uma vez que as unidades espaciais tradicionalmente utilizadas para planejamento têm grande porte. Por exemplo, alguns distritos de São Paulo possuem até 400 mil habitantes, um porte comparável a um grande município como São José dos Campos, dificultando a identificação dos locais com maior nível de carência.

Esse tipo de dificuldade é ainda maior naquelas situações em que é preciso identificar prioridades de investimento quando a cobertura de uma dada política - como a oferta de água, por exemplo - atinge níveis próximos a $100 \%$. Como distinguir os 60 mil domicílios sem água encanada, numa região com 5 milhões de domicílios? A solução para esse tipo de problema passa por um tratamento espacial das informações, porque somente mediante uma análise que leve em conta dados microlocalizados podem-se identificar as principais manchas de ocorrência do problema a ser enfrentado.

A rigor, a utilização de sistemas de informações geográficas e de indicadores microlocalizados para políticas públicas tende a responder um problema básico: onde agir. De fato, para qualquer política pública, tal pergunta é bastante problemática numa área metropolitana com quase 20 milhões de habitantes, como a RMSP. Essa questão, de modo mais específico, remete a três aspectos principais:

- a distribuição dos equipamentos públicos não é consistente com a distribuição da população demandante. Equipamentos podem estar localizados no centro da cidade, distantes dos locais de moradia da população mais pobre. Em outras palavras, entender a distribuição dos equipamentos vis-à-vis à lógica de uma demanda que varia espacialmente e ao longo do tempo é um desafio permanente do ponto de vista das políticas sociais, principalmente se o objetivo da política tem a ver com a democratização do acesso;

- o perfil da população varia ao longo da dimensão espacial, seja em estrutura etária e taxa de crescimento, seja em termos socioeconômicos. Em outras palavras, em função da grande dinâmica demográfica intra-urbana podem existir escolas em locais sem crianças e crianças em locais sem escolas, mesmo se a taxa de cobertura para todo o município se aproxima de $100 \%$. Isso indica que, até quando existentes, equipamentos sociais têm de ser adaptados ao perfil da população local, suas características sociodemográficas;

- riscos sociais são cumulativos. Certas regiões agregam um conjunto significativo de problemas sociais, tais como baixos níveis de escolaridade, domicílios precários, baixa renda, exposição a riscos ambientais, etc. A identificação desses locais é crucial para as políticas sociais voltadas para os grupos sociais mais vulneráveis, tais como as políticas de transferência de renda. Isso indica também que o enfrentamento desse tipo de fenômeno requer políticas que ultrapassem o recorte setorial.

De todo modo, para que tal tipo de análise seja possível, é necessário que as informações que alimentam os estudos sejam consistidas em escalas espaciais menores que os tradicionais municípios e distritos. Foi esse o de- 
safio a que se propôs o projeto do CEM para a RMSP: construir bases de informação na escala intramunicipal e intradistrital, a partir da localização georreferenciada dos eventos estudados; e também produzir os dados que servirão de denominador nos estudos na escala dos setores censitários, a qual permite uma aproximação da escala local. São unidades espaciais, no urbano, que correspondem a um conjunto de quadras, ou a quadras, ou a face de quadras, ou a um conjunto de edifícios em uma face de quadra, ou mesmo a um edifício e seus andares, dependendo de sua densidade demográfica.

\section{O ESPAÇO COMO CATEGORIA}

A tradição das análises espaciais nas ciências sociais e na economia conduziu a análise espacial à esfera dos estudos regionais. Os desafios postos para a solução da questão do desenvolvimento econômico, de um lado, e os efeitos da divisão territorial do trabalho, de outro, pontuaram as discussões sobre a problemática da diversidade do desenvolvimento econômico expressa no espaço. A região pode ser lida como a materialização espacial, pela história, das relações econômicas dentro da esfera da divisão do trabalho, ou seja, as diversidades da organização socioeconômica das sociedades, sua matriz produtiva, as trocas, o mercado de trabalho (estrutura de emprego) e a urbanidade estão gravados no espaço e expressam a forma como o capital se organiza. Assim, a diversidade regional e a maneira como as regiões se organizam e se relacionam aparecem como uma manifestação material das desigualdades dos níveis do desenvolvimento econômico. Procurar decifrar quais as características da estruturação econômica das regiões passou a ser etapa fundamental para entender seu significado nas relações das trocas mercantis na matriz produtiva (regiões funcionais ou polarizadas - redes), bem como elucidar qual o melhor caminho para viabilizar a implantação de políticas econômicas na escala nacional. Uma outra concepção de região é aquela associada à divisão administrativa dos territórios pelo Estado. Fruto da organização política do Estado, essas unidades se impõem como realidades concretas, mais pela forma como as estatísticas oficiais são tratadas e disponibilizadas e menos pela "legitimidade" de suas fronteiras. ${ }^{2}$

O problema da análise regional é que ela somente consegue dar conta, ou servir de subsídio, de políticas quando a ação visa à intervenção na escala regional. Qualquer direcionamento para ações e recursos no objeto local não pode se utilizar do ferramental dessa análise. Grosso modo, a análise regional dá conta de apreender as grandes diferenças - particularidades na escala nacional e entre as nações. Ela seria um excelente "pano de fundo", contudo não oferece a possibilidade do olhar para a tomada de decisões em escala local. Tal passagem do olhar regional para o local, um dos grandes desafios para os gestores públicos, conta hoje com a ajuda fundamental das ferramentas contidas nos Sistemas de Informação Geográfica, que permitem mapear os eventos estudados onde eles realmente ocorrem e cruzar suas informações com dados de outra natureza, podendo ajudar na compreensão de seu conteúdo e de sua distribuição.

Foi sobre essa ordem de preocupações que o projeto CEM teve sua concepção estruturada, ou seja, avançar na escala de observação de como ocorrem os processos socioeconômicos, demográficos e culturais na RMSP, para além da totalidade metropolitana - um além para o interior, voltado para o local.

\section{DESAFIOS PARA A CONSTRUÇÃO DE UM OLHAR ESPACIALIZADO}

A construção para um "olhar espacializado" impõe a necessidade de se pensar como interpretar a relação entre a distribuição da ocorrência de um determinado fenômeno, representado em uma determinada área (óbitos por homicídios em distritos da capital), com as várias dimensões da realidade naquele espaço (como a condição de instrução e renda dos chefes das famílias, e de qualidade dos domicílios). Quando essas informações estão agregadas na escala municipal, ou distrital (a forma tradicional de agregação das informações administrativas e censitárias), perde-se o poder de explicação, pois as correlações possíveis somente poderão se dar a partir dos valores médios dos dados para aquela unidade espacial.

Como exemplo, vejamos a distribuição da taxa de homicídios nos distritos do Município de São Paulo, representado no Mapa 1. As maiores concentrações de óbitos por homicídios, segundo o local de moradia das vítimas, estão nos distritos do sul, no extremo leste da capital e na zona norte, onde evidenciam-se os distritos de Cachoeirinha e Brasilândia. Destacam-se ainda as altas taxas nos distritos da Sé e Brás, na região central da cidade. Tais "regiões" são aquelas que também apresentam os piores indicadores sociais (com exceção dos centrais), o que induziria à conclusão de que os homicídios estariam diretamente ligados a essas condições socioeconômicas. 
No caso, a correlação entre o evento óbito e a realidade renda, por exemplo, se dará a partir das médias distritais o que causa uma série de problemas. Um deles é admitir que o comportamento dos fenômenos analisados apresentase de modo uniforme em todo o território observado e que a correlação dos fenômenos é verdadeira para a totalidade da região.

No caso do exemplo apresentado, o resultado da implementação de políticas que venham a tratar dos efeitos da violência obviamente priorizará os distritos cujas taxas são elevadas. Contudo, como trata-se de territórios com áreas extensas e os recursos públicos são sempre escassos, o problema que se coloca é onde, no interior de cada distrito, devem-se priorizar as ações? Nessa escala de trabalho as prioridades vêm sendo tratadas a partir de demandas locais, geralmente mediadas por pressões políticas. Não é errado o atendimento de reivindicações sociais, contudo existe um setor da sociedade que vive em tal grau de exclusão social, que não tem possibilidade de organização para expor suas necessidades, e geralmente se tem visto nas políticas públicas que as populações mais organizadas é que acabam sendo objeto de programas sociais. A questão da definição de critérios de priorização de investimentos públicos tem surgido como uma demanda do Estado, sobremaneira pelos avanços na democratização das tomadas de decisão e pelo aprimoramento das instâncias de participação popular. Nesse contexto, as informações, como tradicionalmente eram tratadas, não respondem mais às necessidades dos gestores públicos; afinal, observando novamente o Mapa 1, onde naqueles distritos violentos deve-se investir? Somente uma observação: a teoria regional de cunho crítico já alertava para o perigo de fetichização do espaço, com a idéia de que sua identidade se daria a partir de sua característica típica. Nesse mapa as regiões escuras são tipicamente violentas. A pergunta é: será que são realmente assim?

Para responder a essa pergunta, as formas tradicionais de tratamento dos dados espaciais devem alterar-se, e o caminho dessa mudança passa pela fragmentação das unidades administrativas tradicionais (municípios e distritos) e pelo mapeamento dos eventos estudados, com a utilização das ferramentas do Sistema de Informações Geográficas.

A partir das informações da localização dos eventos já é possível identificar a concentração da violência e assim melhor definir a que locais as ações que se desejam devem ser dirigidas. Esse estudo pode avançar e considerar a relação entre o local de residência das vítimas de homi- cídios e a população em seu entorno, ou seja, é possível se reconstruir uma taxa de homicídios utilizando-se como denominador a população total residente nos setores censitários.

O SIG permite agregações de informações de bases cartográficas em objetos geográficos distintos. É possível transpor as informações de população que estão agregadas em setores censitários (um objeto geográfico cuja natureza é uma área) e as informações dos locais de residência das vítimas de homicídios (cujo objeto geográfico é um ponto), para uma terceira unidade geográfica representada, por exemplo, por uma grade, cuja área, no caso do exemplo aqui tratado, é de $250.000 \mathrm{~m}^{2}$ (próxima de uma quadra). A partir daí pode-se criar uma taxa de homicídios para a grade e mapeá-la utilizando-se uma outra ferramenta do SIG, que permite a constituição de manchas construídas a partir de isolíneas (como curvas de nível) de taxas com mesmo valor. O resultado dessa técnica

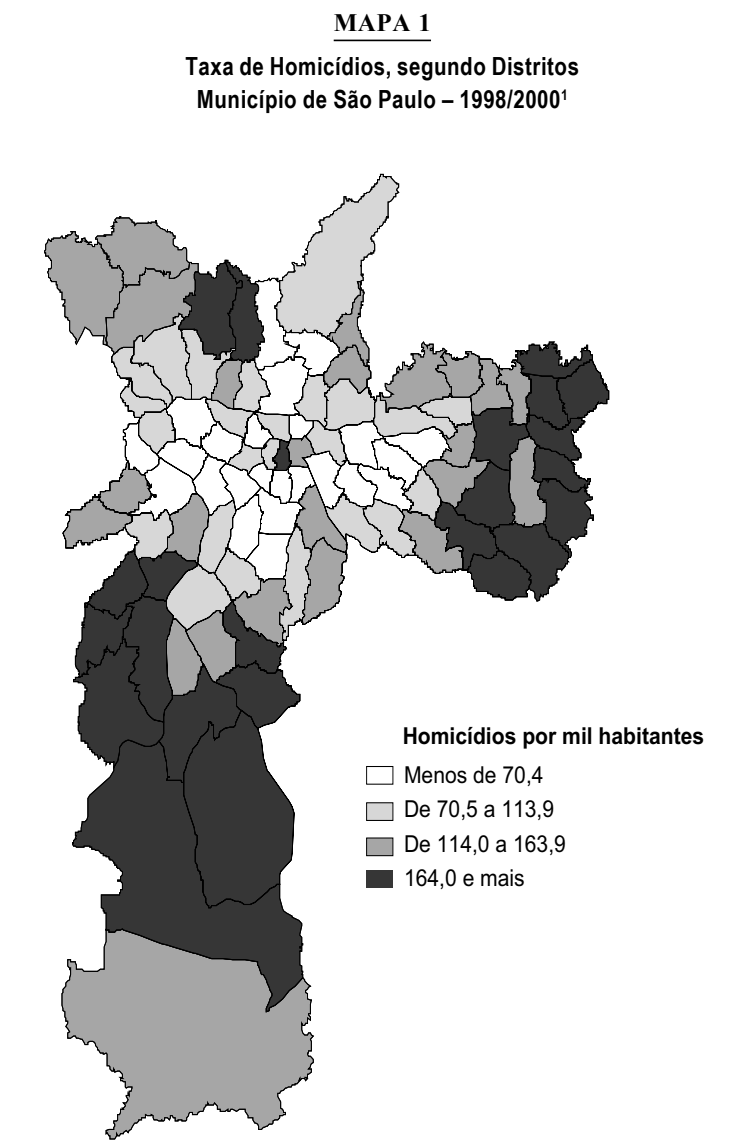

Fonte: Fundação Seade (2001).

(1) Os dados são acumulados para os anos de 1998 a 2000 
cartográfica está representado no Mapa 2. Pode-se constatar que as áreas mais críticas em relação à ocorrência de homicídios estão bem definidas, sendo possível observar na escala local onde elas ocorrem. Como a rigor os SIGs permitem uma ampliação dos mapas a escalas muito grandes, é possível apontar os locais mais críticos com suas quadras e logradouros. O Mapa 3 mostra um detalhe das áreas de maior violência do distrito de Cidade Ademar, onde é possível identificar a malha de logradouros. Para um gestor da área de segurança essa informação é de extrema importância, pois lhe permite uma ação localizada e pontual.

Esse exemplo pode ser estendido para outras situações em que haja interesse de investigação de processo e fenômenos em pequenas escalas, como ocorrem nos projetos e pesquisas desenvolvidos pelo CEM. Segundo o que foi afirmado anteriormente, as ferramentas do SIG possibilitam o cruzamento de informações que se encontram em

\section{MAPA 2 \\ Taxa de Homicídios, segundo Local de Residência das Vítimas Município de São Paulo - 1998/20001}

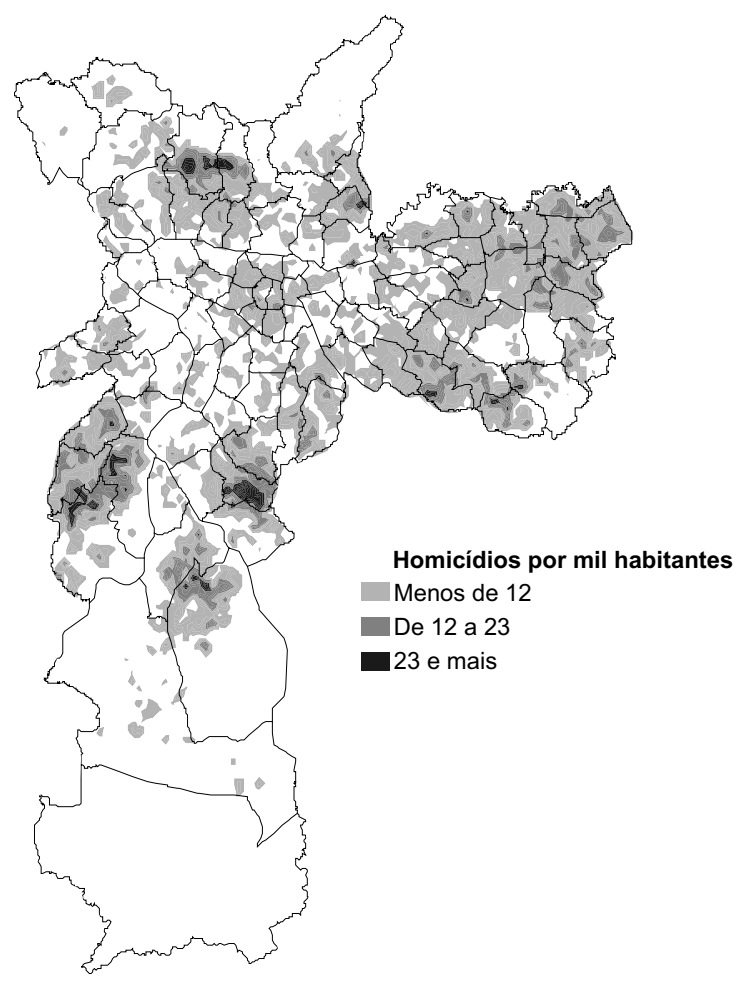

Fonte: Fundação Seade (2001).

(1) Os dados são acumulados para os anos de 1998 a 2000. bases de dados distintas e que possuem unidades espaciais diferentes. Isso possibilita o estabelecimento de correlações espaciais entre esses eventos expressos nos mapas e, do ponto de vista espacial, indicar com mais critério as áreas de intervenção. O grande salto qualitativo no uso da sobreposição de cartografias digitais é a possibilidade de criação de um novo dado, que seria impossível de ser elaborado por simples cruzamento de tabelas, porque as unidades espaciais de agregação das informações são diferentes. $^{3}$

Tal possibilidade de cruzamento espacial dos dados viabilizou a construção de uma série de indicadores extremamente sofisticados, como o Índice de Vulnerabilidade Social elaborado pelo CEM para a Secretaria de Assistência Social do Município de São Paulo. ${ }^{4}$ Contudo, mesmo não chegando a um nível mais sofisticado do uso estatístico das informações espaciais a partir de bases cartográficas distintas, a simples observação do mapa permite a tomada de algum nível de decisão. No Mapa 4, observa-se um exemplo de sobreposição de cartografias que permite uma focalização da ação. No caso está representada a mesma mancha de concentração de homicídio apresentada no Mapa 3, mas acrescida da informação dos setores censitários com maiores índices de vulnerabilidade daquela região. Supondo que a intenção do gestor público seja a implantação de ações sociais que venham mitigar os efeitos da violência e da vulnerabilidade social, ele poderá iniciar sua ação pelos locais onde ocorram a combinação desses eventos. No mínimo, essa informação poderia auxiliar uma investigação focalizada para que daí as decisões fossem tomadas.

Como os sistemas de informação geográfica não se resumem à elaboração de cartografias, mas são, em sua essência, instrumentos que permitem a relação automática entre banco de dados e sua representação espacial, os produtos elaborados no SIG não se limitam aos mapas, mas a um sistema de informações em que os usuários têm plena possibilidade de manuseio. Dessa forma, a escolha das variáveis que serão representadas e os cruzamentos de dados desejados para a construção de indicadores poderão ser feitos livremente pelo usuário, o que permite a elaboração de vários exercícios para a confirmação de hipóteses, ou serve como insumo para a investigação desejada. É por esse motivo que uma importante atividade do CEM, sob a responsabilidade da Fundação Seade, é o treinamento no uso dos SIGs - o eixo condutor da transferência de tecnologia dos envolvidos nas pesquisas e projetos. 
MAPA 3

Taxa de Homicídios, segundo Local de Residência das Vítimas Distrito de Cidade Ademar - 1998/20001

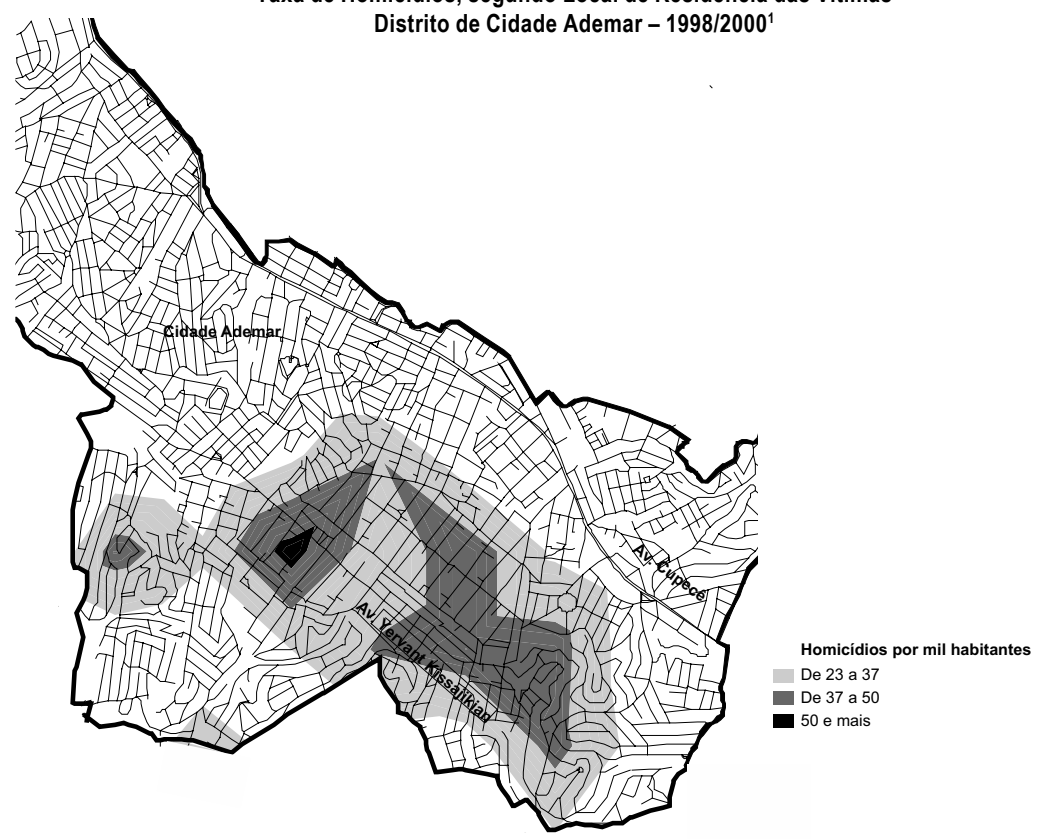

Fonte: Fundação Seade (2001).

(1) Os dados são acumulados para os anos de 1998 a 2000.

MAPA 4

Taxa de Homicídios, segundo Local de Residência das Vítimas e Setores Censitários muito Vulneráveis Distrito de Cidade Ademar - 1998/2000

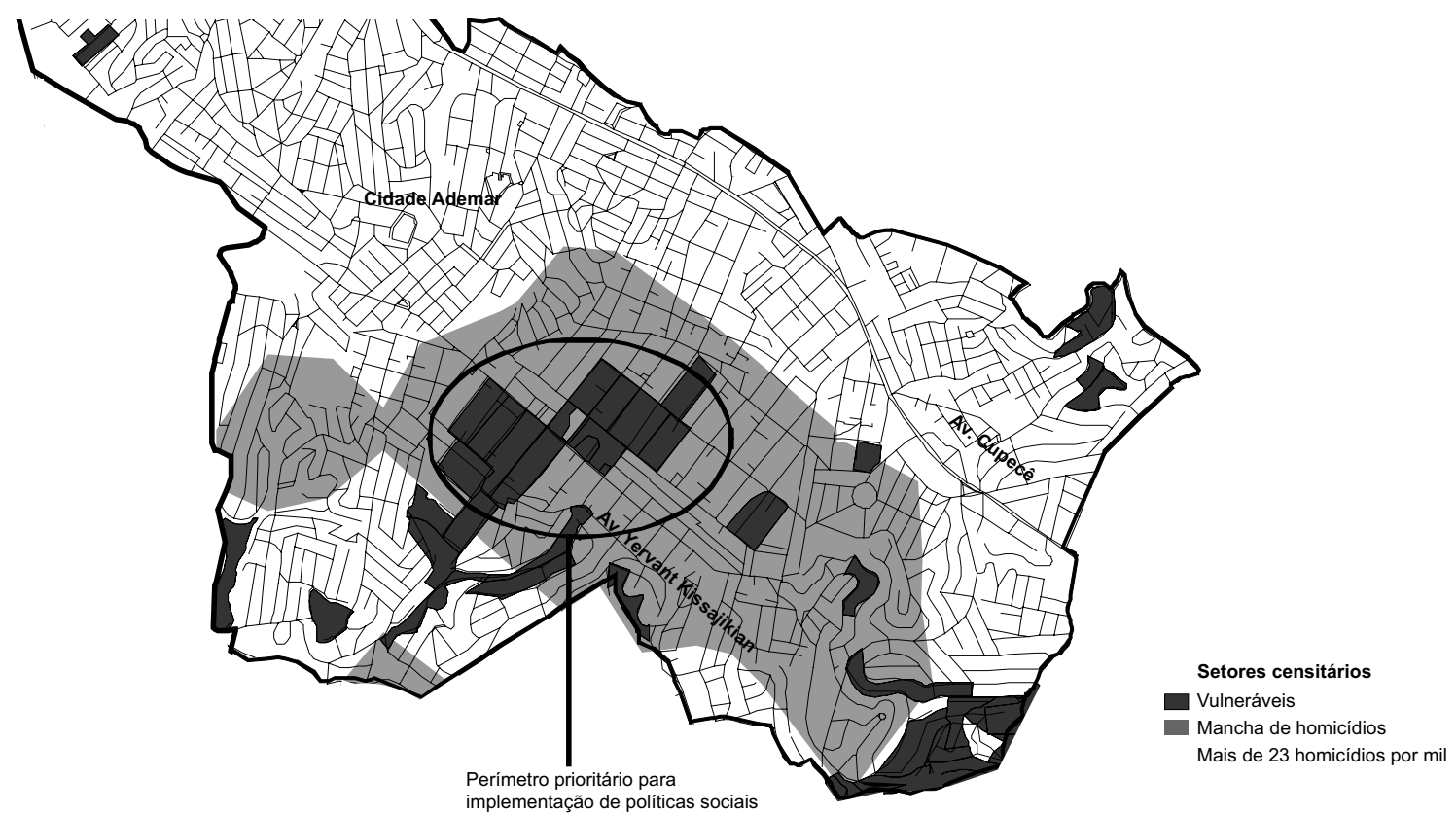

Fonte: Fundação Seade (2001).

(1) Os dados são acumulados para os anos de 1998 a 2000. 
Destaca-se, ainda, que esse conjunto de procedimentos somente é possível se existirem dados desagregados para a escala local associados às cartografias digitais. Por esse motivo, um dos grandes esforços da Fundação Seade e do CEM concentra-se na preparação dessas bases, tendo em vista que elas não se encontram disponíveis para o uso gratuito. Mesmo aquelas existentes em órgãos públicos, como o IBGE, e no mercado apresentam alguns problemas de ordem técnica que necessitam ser corrigidos para as bases serem utilizadas. Assim, dentre desses esforços hoje realizados pelo Seade no projeto CEM, destacam-se: - a vetorização da malha dos setores censitários da RMSP de 1996 e 2000 (os setores de 2000 foram corrigidos para sua consolidação em uma base única e o problema de projeção geográfica foi corrigido, o que implicou uma redigitalização das bases fornecidas pelo $\mathrm{IBGE}^{5}$ );

- a correção e redigitalização da malha dos setores censitários de 1991 da RMSP (a base fornecida pela Emplasa apresentava inconsistência dos atributos geográficos dos polígonos);

- o endereçamento dos equipamentos públicos de saúde e educação na RMSP;

- o endereçamento dos locais de residência dos óbitos, segundo a causa de morte no Município de São Paulo;

- o endereçamento das empresas (do banco de dados da Rais), segundo sua natureza, na RMSP;

- a vetorização para a escala metropolitana da base ambiental de suscetibilidade à erosão, escorregamento, assoreamento e inundação do Projeto Gaia do IPT - Instituto de Pesquisas Tecnológicas.

Esse esforço tem continuidade com a digitalização dos setores censitários urbanos para o municípios com menos de 25 mil habitantes urbanos e para os setores censitários rurais da RMSP (bases não disponibilizadas pelo IBGE); e atualização da base de equipamentos públicos e dos óbitos.

\section{SURVEY E A ANÁLISE ESPACIAL}

Como apresentado anteriormente, uma das inovações do CEM, como Cepid, está no uso de metodologias inovadoras na aplicação e na análise de surveys. Além do conteúdo inovador das investigações sobre a metrópole, a proposta do uso das ferramentas de geoprocessamento, tanto na etapa de definição do universo pesquisado, quanto na de análise dos resultados, permite uma nova abordagem das informações. Isso porque a existência e a possi- bilidade de manipulação de informações em microáreas permitem uma melhor escolha e posterior caracterização desse universo.

Um dos possíveis métodos propiciados pelo uso do Sistema de Informações Geográficas é a aplicação de investigações indiretas, como uso, por exemplo, de telefones para realização da pesquisa. Como é viável mapear, por intermédio do georreferenciamento, os endereços dos telefones pesquisados e associar este mapa à base de dados coletados, é possível estabelecer quais deles serão amostrados (a partir de critérios de localização relacionados aos dados socioeconômicos dos setores censitários); observar se nos resultados obtidos ocorrem padrões espaciais na distribuição dos eventos; correlacionar esses resultados ao banco de dados dos setores censitários; e realizar tratamentos desses dados utilizando as ferramentas de estatísticas espaciais existentes no SIG. Apesar das restrições que essa metodologia impõe (como o acesso da população ao telefone), ela permite um barateamento da investigação, porque desobriga o trabalho de campo e por isso permite que se aumente a amostra da pesquisa tornando-a mais representativa. A Fundação Seade tem se utilizado dessa metodologia em algumas pesquisas e obtido bons resultados.

Um outro exemplo do uso das ferramentas do SIG em surveys é a possibilidade de georreferenciar os procedimentos nas pesquisas diretas. No caso, o uso do SIG poderá facilitar a definição de quem vai ser pesquisado, melhorando a escolha da amostra, porque em vez de utilizar como unidade de pesquisa, por exemplo, os distritos, pode-se usar uma unidade menor constituída por um conjunto de setores censitários; clarear a abrangência territorial da pesquisa (evitando-se os erros comuns da generalização dos resultados encontrados para uma área em que ela não seria significativa); e observar, na análise dos resultados, onde seria possível encontrar padrões espaciais dos dados e investigar as correlações entre esses padrões e as informações socioeconômicas dos setores censitários.

Existe, porém, um uso potencialmente rico da associação entre surveys e o georreferenciamento, que hoje já pode ser realizado na Fundação Seade sem qualquer alteração nas metodologias existentes: o da possibilidade de incorporação de novas informações aos dados coletados em pesquisas diretas. Por exemplo, a partir do endereçamento dos domicílios pesquisados é possível acrescentar informações da distância desses domicílios a qualquer outro ponto relevante que se queira considerar, como a equipamentos públicos, a locais de consumo, ou a pontos de 
ônibus. Ou ainda relacionar as informações coletadas na pesquisa com outros dados, como os censitários. Esse tipo de técnica permite, sem custos elevados, o enriquecimento das informações coletadas no campo, criando novas variáveis de difícil captação direta que podem auxiliar na explicação do comportamento desses dados coletados pessoalmente.

Tais procedimentos, além de agregar vantagens e permitir a melhora nos resultados dos surveys, apresentamse como um instigante desafio que começa a ser vencido.

\section{PROJETOS COM INFORMAÇÕES ESPACIAIS}

A Fundação Seade já vinha desenvolvendo projetos cujo componente estruturador era a produção de sistemas de informações geográficas, que tinham como objetivo instrumentalizar gestores públicos de uma importante ferramenta para sua tomada de decisões. $\mathrm{O}$ amadurecimento desse tipo de demanda na Fundação propiciou a criação da Divisão de Geoprocessamento e Estatísticas Espaciais - Digeo e sua capacitação para participar do projeto CEM como responsável da área de Transferência de Tecnologia em SIG. Dentre esses projetos envolvendo o desenvolvimento de aplicativos em SIG, destacam-se:

- Projeto Priorizando Investimentos em Saneamento elaborado para a Diretoria de Planejamento da Sabesp, cujo objetivo foi a constituição de uma base de dados municipais georreferenciada, com a agregação das informações por grupos de dados (por meio de análises fatoriais) e a agregação de municípios por aglomerados (análise de cluster), segundo suas condições socioeconômicas, de saneamento, demográfica e de saúde. O produto final foi a constituição de um relatório e de um sistema de informações geográficas.

- Projeto Educação - constituição de uma base de dados municipais para a Secretaria de Educação do Estado de São Paulo, com informações educacionais e demográficas. O produto final foi a constituição de um relatório e de um sistema de informações geográficas.

- Entidades Sociais do Terceiro Setor - mapeamento digital das entidades do terceiro setor da zona leste do $\mathrm{Mu}-$ nicípio de São Paulo, para o Sebrae.

- Entidades Culturais - mapeamento digital das entidades e instituições que desenvolvem atividades culturais na Região Metropolitana de São Paulo.

- Projeto Atlas Educacional do Estado de São Paulo constituição de sistema de informações geográficas para a Secretaria Estadual da Educação, no formato de um atlas, na escala de setores censitários, para 96 municípios do Estado. Cada município contou com um conjunto de 20 cartogramas (em papel e em meio digital no formato SIG), em que foram representadas informações de oferta, demanda e desempenho do sistema público de educação.

- Projeto PAC - Programa de Atuação em Cortiços constituição de um sistema de informações geográficas para o CDHU - Companhia de Desenvolvimento Habitacional e Urbano do Estado de São Paulo, com informações de uso do solo e dos dados dos cortiços levantados em pesquisas domiciliares, na escala dos lotes. Para tanto, formam digitalizados mais de 50 mil polígonos correspondentes aos lotes dos setores de atuação do programa. Foi construído um aplicativo de SIG livre por meio da plataforma TerraView, ${ }^{6}$ com as bases do PAC.

- Projeto Fábrica de Cultura - elaboração de mapas digitais para a Secretaria de Cultura do Estado de São Paulo, com a definição de áreas prioritárias de implementação do programa Fábricas de Cultura, no Município de São Paulo.

- Projeto União de Vila Nova/Vila Nair - constituição de um sistema de informações geográficas para o Projeto de Intervenção na Várzea do Rio Tietê, da CDHU, com informações do levantamento socioeconômico nos domicílios da favela. Para isso, mantém digitalizados mais de 5 mil polígonos correspondentes aos lotes, com a agregação do banco de dados da pesquisa. Foram elaborados 17 mapas temáticos com as informações mais relevantes desse banco. À semelhança com o PAC, foi construído um aplicativo de SIG livre por meio da plataforma TerraView, com as bases do projeto.

A esses projetos desenvolvidos pela Fundação Seade, somam-se aqueles realizados diretamente pela equipe de geoprocessamento do CEM e que tiveram apoio da equipe da Digeo. Nesse caso, foram realizados mais oito projetos para as prefeituras de Guarulhos (Secretaria da Educação), Embu (Secretaria da Educação), prefeitura de São Paulo (Secretarias da Educação, Assistência Social, Habitação e de Governo) e Emurb - Empresa Municipal de Urbanização da Prefeitura do Município de São Paulo. O perfil desses projetos foi a constituição de bases georrefenciadas de informações administrativas, a digitalização de bases cartográficas (base de favelas do Município de São Paulo), o apoio ao Ressolo (da Sehab) na digitalização da base de loteamentos irregulares do Município de São Paulo e a elaboração de aplicativos de 
SIG livre, por meio da plataforma TerraView, com as bases de dados dos projetos.

\section{DESAFIOS A SEREM ENFRENTADOS}

Duas ordens de desafios se colocam para os próximos anos de participação da Fundação Seade no desenvolvimento do CEM. O primeiro refere-se à constituição de bases de imagens orbitais de alta resolução para realização de análises urbanísticas e ambientais. Essa tarefa se dará com a participação da Fundação Seade no esforço que o Governo do Estado de São Paulo vem desenvolvendo para a constituição de um banco de dados único de imagens orbitais que hoje encontram-se dispersas por vários órgãos estaduais.

A aplicação no CEM vincula-se ao seu uso como instrumento de análise espacial para a definição de ações locais e como suporte para o mapeamento de componentes ambientais relevantes para a tomada de decisões. Dois exemplos de aplicação da análise espacial por imagens podem ser dados. Um foi a experiência das equipes do Seade e do CEM no uso de imagens para a indicação de áreas prioritárias para a construção de escolas para a prefeitura de Guarulhos. Sobrepostas às informações socioeconômicas, foram plotadas imagens das áreas mais críticas com relação à necessidade de equipamentos de educação, que auxiliaram na busca de terrenos para a edificação das escolas e para o estudo da acessibilidade às áreas municipais onde elas poderiam ser construídas. O outro exemplo refere-se ao potencial uso das imagens para o estudo ambiental de locais com indicadores sociais críticos, ampliando o conceito de risco social para o de "riscos socioambientais", como pode ser o caso das áreas de proteção ambiental e de mananciais, de inundações e escorregamentos, associadas a favelas e loteamentos irregulares. $^{7}$

A segunda ordem de desafios refere-se ao desenvolvimento de aplicações das estatísticas espaciais para análises socioeconômicas. A lógica matemática dos algoritmos que tratam das estatísticas por atributos espaciais trabalha com o conceito de que a localização dos eventos no espaço explica seus atributos, e aqueles outros eventos que estão em seu entorno possuem características semelhantes à sua. A diferenciação dessas características dá-se pelo aumento da distância. Do ponto de vista geográfico essa lógica é clara, pois a altitude de um determinado objeto deve ser muito semelhante à de um vizinho próximo; o mesmo também deve acontecer com a temperatura, a pres- são atmosférica, a ocorrência mineral, o solo e até com a cobertura vegetal. Contudo, dificilmente essa lógica pode se reproduzir para fenômenos sociais, com exceção da área de saúde (o contato entre pessoas produz um efeito epidemiológico dos eventos), porque os processos socioeconômicos e culturais possuem uma espacialidade que independe da sua condição topológica (a influência dos vizinhos é menos importante na determinação do comportamento de seus atributos). O uso das estatísticas espaciais no tratamento de dados socioeconômicos, porém, servem mais para mitigar o efeito ecológico da rigidez da organização dos dados em unidades administrativas (conforme visto no Mapa 1) e menos para a imputação de dados, como ocorre para os fenômenos da natureza. Esse uso mais "simples" das estatísticas espaciais (como na análise de superfícies e de vizinhança) tem auxiliado sobremaneira nos tipos de representação dos eventos analisados. Um exemplo disso são os Mapas 2 e 3, nos quais foi aplicada a técnica de análise de superfície, que proporciona a visualização da hierarquização da ocorrência de eventos.

Existe ainda um outro campo de desafios no uso das estatísticas espaciais que se refere à criação de indicadores em microáreas. Se as metodologias de construção de taxas estão consolidadas quando há um grande número de eventos e quando o denominador utilizado é aceito universalmente (uma população qualquer), elas não existem quando os dados são em menor volume (como ocorre na escala dos setores censitários). Alguns estudos já realizados na Fundação Seade mostram que o cálculo das taxas de homicídio por setores censitários tem resultados não muito satisfatórios, porque sua variabilidade é muito grande. Algumas alternativas estudadas indicam que a melhor solução é a agregação de setores, que pode-se dar de várias formas, dependendo do estudo feito. Isso indica, ao contrário do que ocorria anteriormente com o uso das ferramentas do SIG, que se pode ter várias taxas de homicídio, conforme o olhar que se lance sobre o tema. Mas o fato é que essas metodologias ainda devem ser aprimoradas, pois as aparentes soluções para o efeito ecológico do "grande número" (Souza, 2000) podem se transformar em um outro problema.

\section{NOTAS}

1. A Fundação Seade também participa como colaboradora no projeto Estudos do Trabalho; para mais informações consultar o site do CEM $<$ www.centrodametropole.org.br>. 
2. Existem inúmeros estudos que utilizam o conceito de divisão territorial do trabalho, mas ao discutir a diversidade regional do Brasil reiteram as unidades macrorregionais hoje existentes, sob a alegação de que os dados disponíveis somente existem para tais unidades (mesmo quando se voltam para unidades intraestaduais, o que prevalece são as Meso e Microrregiões homogêneas - um conceito de região oriundo da "Escola Francesa", marcadamente fisiográfico).

3. Como ocorria quando se desejava, por exemplo, criar algum tipo de indicador de saúde, porque as unidades de saúde possuíam uma área que não correspondia à dos distritos censitários, ou seja, não era possível o estabelecimento de um denominador.

4. Ver informações no site do CEM: <www.centrodametropole.org.br>.

5. O IBGE teve papel fundamental no processo de digitalização e correção das bases dos setores censitários de 1996 e 2000, pois possibilitou o acesso aos arquivos de mapas em papel dos setores de $1996 \mathrm{e}$ forneceu a base digital da malha de setores censitários de 2000, assim como de seu banco de dados.

6. Aplicativo desenvolvido pelo Instituto de Pesquisas Espaciais - INPE $<$ www.inpe.dpi.br>.

7. Os primeiros estudos avaliando a situação ambiental das porções mais pobres do Município de São Paulo já começaram, com o cruzamento dos dados da condição socioeconômica dos setores censitários, das favelas mapeadas pelo CEM e dos loteamentos irregulares digitalizados pelo Ressolo, com os dados do mapa de suscetibilidade do Projeto Gaia.

\section{REFERÊNCIAS BIBLIOGRÁFICAS}

CHOLEY, R. Modelos integrados em geografia. Rio de Janeiro: Livros Técnicos e Científicos; São Paulo: Ed. Universidade de São Paulo, 1974.

FUNDAÇÃO SEADE. Sistema Estadual de Análise de Dados. Mapa dos óbitos no municipio de São Paulo, segundo as causas. Dados acumulados para os anos de 1998, 1999 e 2000. São Paulo: 2001.
HARVEY, D. Modelos da evolução dos padrões espaciais na geografia humana. In: Edward Arnold Ltda., 1969.

IBGE. Instituto Brasileiro de Geografia e Estatística. Censo Demográfico de 2000. Rio de Janeiro: 2000.

LAVINAS, L.; CARLEIAL, L.; NABUCO, M. (Orgs.). Reestruturação do espaço urbano e regional no Brasil. São Paulo: Hucitec/ Anpur/Annablume, 1993.

LLOYD, P.; DICKEN, P. Location in space: a theoritical approach to economic geography. New York: Harper and Row Publishers Inc.; 1972.

SOUZA, G.C. As populações nos estudos e relatórios de impacto ambiental. Ou, da demografia dos grandes números à demografia dos pequenos números. In: XII ENCONTRO NACIONAL DE ESTUDOS POPULACIONAIS, Anais... Caxambu, 2000.

TORRES, H.G.; SOUZA, G.C. Primary education and residential segregation in the municipality of São Paulo - a study using geographic information systems. International Seminar on Segregation in the City, Lincoln Institute of Land Policy, Cambridge, MA, 2001.

TORRES, H. G. Social policies for the urban poor: the role of population information systems. Mexico city: UNFPA Country Support Team for Latin America and Caribbean. Working Papers Series, n.24, 2002.

Gustavo de Oliveira Coelho de Souza: Sociólogo e Geógrafo, chefe da Divisão de Geoprocessamento e Estatísticas Espaciais da Fundação Seade, Professor do Departamento de Geografia da PUC-SP (gcoelho@seade.gov.br).

Haroldo da Gama Torres: Demógrafo, Coordenador do Núcleo de Geoprocessamento e Informações do Centro de Estudos da Metrópole, Consultorda Fundação Seade (hgtorres@uol.com.br). 